INTER-LEGERE

A MEMÓRIA COMO PROMESSA: EXPERIÊNCIAS DA FORMAÇÃO DE

PROFESSORES PARA O ENSINO DE SOCIOLOGIA

Geovana Tabachi Silva

\title{
A MEMÓRIA COMO PROMESSA: \\ EXPERIÊNCIAS DA FORMAÇÃO DE PROFESSORES PARA O ENSINO DE SOCIOLOGIA
}

\author{
Geovana Tabachi Silva ${ }^{1}$ \\ "O passado, a rigor, é uma alteridade absoluta, que só se torna \\ cognoscível mediante a voz do narrador"
}

(Ecléa Bosi, 2003).

\section{RESUMO}

Este trabalho tem como finalidade estimular o discente do curso de licenciatura em Ciências Sociais e futuro professor de Sociologia no ensino médio a exercitar sua imaginação sociológica. Levando em consideração a variedade de experiências que o ensino de Sociologia pode proporcionar, utilizam-se como instrumentos para suas reflexões e modos de agir as noções de memória e patrimônio cultural enquanto categorias circunstanciais.

\section{ABSTRACT}

This paper aims to stimulate the student of social sciences and future teacher in sociology in the high school to exercise their sociological imagination, given the variety of experiences that teaching sociology can provide. To the analysis and proceedings, the concepts of memory and cultural heritage, while circumstantial categories, are used.

\section{CAMINHOS PERCORRIDOS}

Este texto é fruto de experiências relacionadas a um conjunto de atividades envolvendo campos temáticos sobre memória, patrimônio e formação de professores para o Ensino de Sociologia. A trajetória dessas experiências transcorreu de 2011 até o segundo semestre de 2015, tendo como público envolvido os alunos do Curso de Licenciatura em Ciências Sociais, da Universidade Federal

Professora do Departamento de Ciências Sociais, Instituto de Ciências da Sociedade e Desenvolvimento Regional, Universidade Federal Fluminense, Campos dos Goytacazes (COCESRUFF); membro do Laboratório de Pesquisa e Ensino em Ciências Sociais (LAPECS); Mestre em Antropologia (UFF); doutoranda no Programa de Pós-Graduação em Políticas Sociais, na Universidade do Norte Fluminense (PPGPS-UENF). 
Fluminense (UFF), em Campos dos Goytacazes/RJ. Embora as atividades apresentem temporalidades distintas e tenham percorrido tanto as disciplinas obrigatórias quanto as optativas, além de projetos de extensão e pesquisa, monitoria, minicursos, oficinas e visitas técnicas, culminaram em reflexões que expressaram olhares diversos e que traduziram o interesse, a preocupação e as expectativas dos alunos licenciandos com a sua futura prática profissional ${ }^{2}$.

Os conhecimentos aqui apreendidos são fruto de reflexões sobre teorias e conceitos, conforme abordado nas Orientações Curriculares Nacionais (OCNs), (BRASIL, 2006), quanto da viabilidade pedagógica ao se propor exercitar a imaginação sociológica (MILLS, 1975) e atuar no diálogo com os alunos do ensino médio nas aulas de Sociologia. Por conseguinte, discorrer sobre memória é relevante na medida em que se exaltam lembranças e esquecimentos, relatos de histórias de vida, experiências e descobertas, de infância ou as mais recentes, sendo possível, assim, agir como um artesão intelectual ao usar a experiência de vida no trabalho continuamente e, dessa maneira, relacionar esses conhecimentos com os campos do patrimônio cultural e da educação. "Dizer que pode 'ter experiência' significa que seu passado influi e afeta o presente, e que define a sua capacidade de experiência futura".

Para desenvolver essa ideia, inicialmente, tecerei algumas considerações sobre os conceitos centrais do texto, como memória, patrimônio e imaginação sociológica. Na parte subsequente, serão apresentadas algumas ações que foram realizadas nas disciplinas e atividades citadas com os discentes, futuros professores de Sociologia no ensino médio. As atividades consideraram o tema da memória como estímulo ao exercício da imaginação sociológica e possibilidade de ensino, a partir de temas conhecidos e não tão distantes do cotidiano, ou seja, mais uma possibilidade de estranhamento e desnaturalização de realidades sociais, conforme sugerido nas OCNs, bem como no debate atual sobre a Base Nacional Comum Curricular (BNCC), no componente curricular de Sociologia.

\footnotetext{
${ }^{2}$ Agradecimentos aos alunos Camila Dalvi, David Pereira, Eloá Carvalho, Gabriela Vieira, Jhennifer Almeida, João Paulo Vigneron, Yolanda Grafée, Marcia Jordana, Mariana Domingues, Michelle Piraciaba, Priscila, Raíssa Moquiche e Williams Luna.
} 
Os pressupostos metodológicos das OCNs no componente curricular de Sociologia possibilitam o exercício científico constante do estranhamento de fenômenos sociais vistos como naturalizados, triviais e sem a necessidade de explicação, na medida em que estimulam o questionamento e a problematização. Por esse viés, busca-se acionar experiências outras ao utilizar como instrumento para as reflexões e modos de agir as noções de memória e patrimônio cultural enquanto categorias circunstanciais.

A estratégia metodológica adotada para que fosse possível o relato das experiências, além de aulas teóricas, com leituras e debates sobre ideias e autores, rodas de conversa com convidados, caracterizou-se pela realização de visitas técnicas e city tour a pé pelas ruas, praças, centro cultural, museus e demais espaços urbanos e patrimônios das cidades de Campos dos Goytacazes e Rio de Janeiro.

\section{A MEMÓRIA COMO PROMESSA}

Dialogando com a teoria da imaginação sociológica de Mills (1975, p. 11) e analisando os saberes dos discentes, podemos ressaltar que "não é apenas de informação que precisam [...] não é apenas de habilidade da razão que precisam", porém de alternativas que os possibilitem compreender transformações contemporâneas tão rápidas e com complexidades diversas, como aquelas relacionadas ao campo da experiência moral. Desse modo, o uso da imaginação sociológica pode se caracterizar como importante ferramenta na percepção sobre a tensão entre ações individuais e padrões que buscam universalização, em que as particularidades das perspectivas sobre o mundo possam se tornar mais evidentes, sendo ampliadas as consciências entre suas vidas e a sociedade, entre sua biografia e a história, à medida que podem reconhecer as relações situadas num campo de interações mais amplo.

O que precisam, e o que sentem precisar, é uma qualidade de espírito que lhes ajude a usar a informação e a desenvolver a razão, 
a fim de perceber, com lucidez, o que está ocorrendo no mundo e o que pode estar acontecendo dentro deles mesmos (MILLS, 1975, p. 11).

Seguindo esse percurso de análise, e ainda considerando o mesmo autor, ao se exercitar a imaginação, experimenta-se uma forma mais frutífera de consciência tanto de si quanto aquelas relacionadas à estrutura mais ampla da vida social, em que as certezas e decisões que pareciam sólidas tornam-se perturbações ameaçadoras de valores (MILLS, 1975). Em outras palavras, ao se incorporar a imaginação sociológica, é possível afirmar o estímulo de mais de uma compreensão sobre os contextos vivenciados e se reconhecer as variedades de experiências que o ensino pode produzir, tendo em vista, ainda, a diversidade de significados e interpretações pertinentes às relações sociais.

Contudo, em que medida o uso da memória como campo de conhecimento pode proporcionar perturbações? Qual a relevância desse campo na formação de professores para o ensino de Sociologia? $\mathrm{Na}$ expectativa de dar conta dessas questões, podemos declarar que a memória pode ser usada como estratégia mediadora para as reflexões da prática e considerando-se que busca articular conhecimento acumulado nas experiências vividas num constante exercício da práxis.

A complexidade da realidade contemporânea coloca 0 desafio de se incorporarem à formação de professores diferentes leituras do mundo e dos diversos contextos culturais, o conhecimento da pluralidade de significações e a noção da multiplicidade de saberes e sujeitos inseridos no cotidiano da escola. Assim, o trabalho com a memória possibilita o resgate de lembranças, imagens, ideias, sensações, sentimentos e experiências, tanto individuais quanto coletivas, que levam a lugares e tempos do passado. Essas memórias compõem o acervo cultural de diferentes grupos sociais, provocando, desse modo, o exercício da alteridade, primordial para a prática docente (PEREZ, 2009).

Para o professor de Sociologia, esses pressupostos podem ser considerados enormes desafios à sua prática intelectual, pedagógica e metodológica, não sendo menos provocador para a escola, os alunos e a disciplina. Nesse contexto, a 
pesquisa se destaca como sendo um bom instrumento no trabalho de compreensão científica do cotidiano do aluno e de sua comunidade.

Com esse entendimento, compreende-se que o trabalho de formação de professores por meio da memória está articulado ao campo do patrimônio, constituindo-se enquanto mais um olhar investigativo, epistemológico, que potencializa a pesquisa, o reconhecimento das diferenças e da cidadania.

Sobre a noção de memória, pode-se afirmar que a sua compreensão está associada à ideia de recordar, não devendo ser juntada a algo do passado e formulada em moldes clássicos, sob uma forma simples, imóvel, unívoca. Ao contrário, trata-se de um fenômeno complexo, em permanente processo de construção, inserido em um campo de lutas e de relações de poder. Ainda que a memória seja patrimônio inacabado, compõe a teia de significados resultante da associação entre lembrança e esquecimento (GONDAR; DODEBEI, 2005).

Nos estudos de Maurice Halbwachs (1990), a memória não se apresenta como campo de luta, de conflitos, mas como um fenômeno de interiorização individual, bem como uma construção social e um fenômeno coletivo, que acentua as funções desempenhadas pela memória comum, de reforçar a coesão social pela adesão afetiva do grupo. Sendo uma construção social, a memória é, em parte, modelada pela família e pelos grupos sociais, estruturando-se e inserindo-se na memória coletiva.

Em Pollak (1989 apud GONÇALVES, 2012), o chamado campo discursivo dos patrimônios culturais é bastante complexo e constituído por uma série de ambiguidades, contradições e paradoxos, configurando-se, muitas vezes, a exemplo da memória coletiva, como um "campo de batalha".

No entendimento de Gonçalves (2012), é importante considerar o sentido moderno da categoria patrimônio, pelo qual esta se constitui em cultura ou em formas específicas de inventar a cultura:

Pensar os patrimônios como "culturas" significa nos perguntarmos pela linguagem dos patrimônios, ou pelos vocabulários a partir dos quais objetos materiais, lugares, práticas sociais ou formas de vida são transformados, ou constituídos, social e discursivamente, em "patrimônios" (GONÇALVES, 2012, p. 66). 
Desse modo, é importante saber tanto sobre as funções identitárias do patrimônio e sua memória quanto a respeito dos processos de sua produção e dos seus efeitos na vida social e cultural. Ainda buscando compreender a concepção de patrimônio, Gonçalves (2012) acrescenta que

[...] podemos nos permitir pensar o patrimônio não mais como um dado situado num tempo ou num espaço distante, mas como um processo presente, incessante, imponderável e interminável de reconstrução (GONÇALVES, 2012, p. 69).

Para Teixeira (2014, p. 17), "tudo aquilo que envolve o patrimônio cultural supõe um processo de seleção pautada em critérios éticos e políticos que passam pelo sentimento de pertencimento e pela memória". A autora ainda afirma que, desde os anos 1980, há uma forte inserção de bens referenciais da cultura popular no tradicional modelo da política moderna, isto é, no acervo da elite dominante. Tal fato demonstra que as manifestações e representações da cultura popular de um grupo social passaram a ser reconhecidas, na medida em que existe um deslocamento do epicentro dos bens patrimoniais históricos, que comumente foram representados pelas edificações do clero, do Estado e da elite (TEIXEIRA, 2014).

Embora a expressão patrimônio cultural esteja associada quase sempre a prédios e monumentos antigos, relíquias guardadas em museus e obras de arte consagradas, o conceito foi expandido a partir da Constituição de 1988, em seus artigos 215 e 216 . Os bens materiais, como igrejas e casarios, apelidados de "pedra e cal", contam parte das histórias dos grupos sociais. Porém, há outro universo de memórias e conhecimentos, parte constitutiva dessas histórias, que complementa e contribui para os registros: são eles os bens intangíveis ou imateriais (FONSECA, 2003).

A seguir, descreverei algumas experiências de ensino, tecendo as relações entre memória e patrimônio, conceitos que foram utilizados como categorias de pensamento em propostas de ensino nas aulas de Sociologia, tendo em vista o entendimento da vida social e cultural. Alguns objetivos comuns caracterizam as 
produções que foram elaboradas individualmente, como, por exemplo, proporcionar reflexões que compreendem conhecer e reconhecer, aprimorar e valorizar a herança cultural, assim como fortalecer os sentimentos de identidade. Além disso, a preservação de um bem cultural se articula ao seu conhecimento e ao seu uso social.

Retornando a Gonçalves (2009, p. 31), o estudo das categorias de pensamento é uma contribuição original da tradição antropológica, sendo tarefa do pesquisador verificar quais conexões de sentido podem ser encontradas em contextos distintos, históricos e culturais. Para o autor, o patrimônio pode ser considerado um bem cultural "bom para agir" e que faz a mediação entre passado e presente, em que o bem cultural "não existe apenas para representar ideias e valores abstratos a ser contemplado. O patrimônio, de certo modo, constrói, forma as pessoas".

Considerando os objetivos que caracterizaram os trabalhos individuais dos alunos, nota-se que estes contemplam os pressupostos metodológicos das OCNs (2006) pautados em teorias, temas e conceitos, em que um tema não pode ser tratado sem o recurso a conceitos e a teorias sociológicas, senão se banaliza. Estes permitem variados recortes e devem servir para orientar as reflexões do professor a partir das propostas pedagógicas da escola, assim como das demandas da comunidade escolar.

Ao se tomar um conceito - recorte conceitual -, este tanto faz parte da aplicação de um tema quanto tem uma significação específica de acordo com uma teoria, do contrário os conceitos sociológicos seriam apenas um glossário sem sentido, pelo menos para os alunos do ensino médio (BRASIL, 2006, p. 117).

\section{EXERCITANDO O ESTRANHAMENTO}

O início da experiência ocorreu durante a disciplina optativa "Educação e Patrimônio Cultural - Tópicos Especiais em Sociologia I", em que o debate acerca da memória marcou as aulas, ocasionando diversas reflexões aos discentes, a partir das quais Ihes foi solicitado como avaliação final um trabalho em que a memória e o 
patrimônio fossem abordados como propostas de ensino. Surgiram propostas que marcavam a memória e o patrimônio relacionando temas como rituais e festividades, patrimônio industrial, étnico e cultural, a cidade como patrimônio, além de memórias de escola.

Posteriormente, o projeto de extensão "O Cinema vai à Escola" procurou relacionar memória e questões étnicas, de modo que os alunos que iniciavam o estágio docente deveriam elaborar suas aulas a partir de vídeos e curtas com abordagens sobre a questão indígena ou afro-brasileira. Na sequência, o trabalho de monitoria $^{3}$ da disciplina Pesquisa e Prática de Ensino I desenvolveu no 5o período um registro com os relatos dos alunos sobre suas memórias de escola, resultando na elaboração do vídeo "A memória da experiência escolar como objeto de estudo". Essa elaboração teve como objetivo estimular os alunos a refletirem sobre suas recordações de escola e, assim, torná-las parte de seu processo de formação docente, inserindo, posteriormente, a temática em seus planos de ensino.

Ainda em 2013, incluindo o ano de 2014, foram realizados dois minicursos e uma oficina, ambos intitulados "Memória, Educação e Cultura", com a participação ativa de outra professora do departamento de Ciências Sociais ${ }^{4}$. Em 2015, o projeto de desenvolvimento acadêmico do PROAES (Programa de Assistência Estudantil) deu início a uma observação que teve por objetivo preliminar identificar e compreender os processos educativos inseridos numa escola de samba de Campos dos Goytacazes, a partir de uma abordagem etnográfica, em que a memória e o patrimônio foram tomados como conceitos centrais ${ }^{5}$.

Os trabalhos abordaram diferentes contextos, tendo por objetivos comuns proporcionar nas aulas de Sociologia reflexões que visem conhecer, aprimorar e valorizar a herança cultural, além de fortalecer os sentimentos de identidade de alunos do ensino médio. Além disso, possibilitaram o exercício da criatividade, tanto dos alunos quanto, em especial, do professor regente da disciplina, na medida em

3 O trabalho foi desenvolvido pela aluna e monitora da disciplina, Gabriela Ferreira Vieira, tendo concluído o curso em dezembro de 2014.

4 Os minicursos e oficinas foram pensados e elaborados em conjunto com a Professora do Departamento de Ciências Sociais da UFF-Campos, Dra. Andrea Lúcia da Silva de Paiva.

${ }^{5}$ Devido à greve dos docentes e técnicos que foi deflagrada em maio de 2015 , seguindo até outubro, a pesquisa não seguiu o cronograma inicialmente previsto. 
que ele têm a oportunidade de (re)significar sua história e suas memórias, num constante exercício do estranhamento.

As experiências pedagógicas descritas a seguir se confirmam nas narrativas dos alunos. Estes estavam regularmente matriculados em disciplinas obrigatórias, optativas ou inseridos em projetos de pesquisa ou extensão. Para preservar suas identidades, a identificação é fictícia, sendo atribuídas as letras " $X$ ", "Y", "Z" e "W" para cada um em seu respectivo relato.

Considerando a ideia de patrimônio intangível e imaterial, uma das alunas desenvolveu um vídeo e um texto com registros sobre um importante componente da sociedade brasileira: o indígena. $O$ trabalho se concentrou na emblemática figura da estátua do índio goytacá, anteriormente localizada na BR 101, no trevo que dá acesso à entrada da cidade de Campos dos Goytacazes. Embora a etnia tenha sido extinta há algum tempo, ela é parte de uma memória coletiva que tende a manter viva a importância desses antepassados.

O que me motivou a tratar da "Estátua do Índio" nesta disciplina foram, justamente, minhas próprias memórias. Com a visita que empreendemos ao Arquivo Público como parte da atividade da disciplina, pude observar a estátua, e logo fui tomada pela emoção de lembranças da minha infância, da minha mãe, enfim, de histórias pessoais que me moldaram; também a observação de que amigos (geralmente da minha faixa etária), parentes, vizinhos, enfim, as pessoas com quem eu iniciava a conversa sobre o índio, possuírem, também, opiniões e lembranças muito próximas às minhas. [...] além disto, a importância material da estátua, que é imponente, grande, e obra artística; [...] à maneira com que o poder público rapidamente, em poucos dias, preparou um relatório da defesa civil e logo empreendeu a retirada, sem consulta popular; por fim, ao destino dado à estátua, deixada ao relento, exposta ao tempo, chuva, sol e sua avançada deterioração por ausência de cuidado e interesse em preservá-la (Aluna "X", do $5^{\circ}$ período, 2011).

O vídeo desenvolvido pela aluna trata-se de um curta com cerca de cinco minutos de duração, contendo três breves relatos de senhores campistas, além de imagens da estátua em momentos distintos, antes e após a sua retirada do trevo. $\mathrm{O}$ registro teve como objetivo tornar-se recurso didático em aulas de Sociologia e, como afirma a discente, possui "várias possibilidades de alinhavo, seja para tratar da 
questão patrimonial, da questão da memória, da etnia, da identidade, do poder público, do descaso, enfim, [...]", de processos econômicos de desenvolvimento.

Em outro trabalho, a abordagem volta-se para a Festa da Polenta, na pequena cidade de Venda Nova do Imigrante - ES. Conforme destaca a discente que o desenvolveu, o evento é uma homenagem à imigração italiana ocorrida no município no século XIX e "abrange diversas gerações e etnias, sendo relevante compreender seu papel como constituinte de uma identidade e pensar como o saber é transmitido de geração a geração". Em sua abordagem, a aluna afirma que as "festas populares são consideradas como tradições constituintes da resistência de um povo em defender sua cultura e seus costumes". Nessa direção, para construir sua proposta de ensino, a aluna fez uma pesquisa de campo e, para compreender melhor o evento, utilizou a noção de "lugar de memória", em que procurou entender "o que é relevante à memória local que merece ser evidenciado na festa e o que é de certo modo esquecido". A partir dessa análise, a discente propôs elaborar um projeto interventivo de exposição da Festa da Polenta, tanto no próprio evento quanto em escolas da rede municipal.

A proposta de levar às escolas se dá por acreditar que esta seria uma forma dos alunos saberem mais sobre a história de imigração do seu município, além de que, com isso, seria possível levantar discussões acerca de diversidade cultural, diversidade étnica, costumes, valores (Aluna "Y", do 5o período, 2011).

Outra proposta que também merece destaque é o projeto de educação patrimonial a ser realizado nas escolas. De acordo com a discente, diz respeito a uma oficina de memória que inclui moradores de todas as idades, a qual acontece durante um final de semana no quilombo situado em Imbé, área rural do município de Campos - RJ.

A proposta inclui realizar "mapas mentais", ou seja, percorrer o território com os moradores para que eles mesmos possam desenhar um mapa de identificação desses "espaços de memória". Desde o local onde ficavam os instrumentos de tortura de escravos, a casa de farinha, a sede das fazendas, a trajetória das procissões e das folias 
de reis, entre outros. Esse tipo de metodologia é utilizado em outras comunidades quilombolas e permite 0 autorreconhecimento dos próprios moradores e serve, ainda, como ferramenta para as demandas de direitos e reconhecimento e de políticas públicas específicas (Aluna "Z", do 5o período, 2011).

Ao se "recordar" de situações vivenciadas nas dinâmicas da escola, é possível propor outras análises e práticas distantes da realidade encontrada anteriormente. Nesse sentido, ao relatar os casos vividos, tem-se a oportunidade de pensar no cotidiano escolar enquanto espaço de elaboração de outras experiências, como recurso "mediador" para uma análise crítica da prática pedagógica, e, consequentemente, sobre a postura do docente como profissional da educação.

Foi diante dessa premissa que se desenvolveu o trabalho de monitoria da disciplina "Pesquisa e Prática de Ensino I". Durante as aulas e no trabalho de orientação da monitora, notamos a recorrência de comentários e lembranças sobre os tempos de escola. A partir daí, inseri no conteúdo programático da disciplina alguns momentos destinados a tratarmos das memórias de escola. Para desenvolver a atividade, adotamos como metodologia o agendamento de algumas datas em que fosse possível nos fixarmos melhor sobre o tema. Na ocasião, cada discente seria responsável por levar para a aula objetos, bem como relatar práticas, situações, concepções e pessoas que indicassem sobre suas recordações de escola. $\mathrm{O}$ registro da atividade coube à monitora da disciplina, que se propôs a gravar cada relato utilizando câmera filmadora.

Observamos o quanto foi possível produzir conhecimento a partir de experiências relembradas e das emoções vivenciadas, na medida em que a memória também pode ser reconhecida como um saber. A reflexão a respeito dos caminhos percorridos até o ingresso na universidade e da escolha do curso de licenciatura corresponde a uma das temáticas que orientaram a narrativa.

A experiência sobre memórias de escola também mostrou a importância de se compartilharem os conhecimentos produzidos no espaço escolar mediante a socialização das memórias individuais, indicando o quanto as lembranças pessoais tornam-se memórias coletivas, passando a fazer sentido para os envolvidos no processo. 
Nessa perspectiva, podemos considerar a escola como um "lugar de memória". A expressão atribuída ao historiador francês Pierre Nora (1993, p. 21-22), apresenta uma tríplice acepção: material (em que a memória social pode ser apreendida pelos sentidos), funcional (porque tem a função de alicerçar memórias coletivas) e simbólica (em que essa memória coletiva se expressa). Embora sejam simultâneas, desenvolvem-se em graus diversos, resultando em lugares complexos e híbridos. Para o autor, os locais de memória são necessários na medida em que o passado está ameaçado, sendo preciso produzir arquivos para guardar, produzir memórias para conservar: "lugares de memória são sinais de reconhecimento e de pertencimento de grupo numa sociedade que só tende a reconhecer indivíduos idênticos" (NORA, 1993, p. 13). Esses lugares

nascem e vivem do sentimento que não há memória espontânea nas sociedades atuais, que é preciso criar arquivos, organizar celebrações, manter aniversários, pronunciar elogios fúnebres, notariar atas, porque estas operações não são naturais (NORA, 1993, p. 7).

As experiências relacionadas à prática educativa envolvendo a memória, a formação de professores e a interculturalidade "foram realizadas como ferramenta teórica a serviço da ruptura do paradigma escolar fundado no monoculturalismo e no etnocentrismo" (PÉREZ, 2009, p. 253). Essas atividades, além de se distanciarem de olhares etnocêntricos e atenderem às exigências legislativas ${ }^{6}$, também se relacionaram à memória, à tradição e à ancestralidade, lidando de forma mais específica com os grupos afro-brasileiros e indígenas.

Desse modo, os conhecimentos sobre esses grupos foram ressaltados a partir de aulas, visitas a museus e exibição de objetos e vídeos, culminando com a participação e a palestra de uma liderança indígena guarani ${ }^{7}$, que enfatizou a importância da recuperação da memória histórica de seu povo, a reafirmação de sua identidade étnica e a valorização de suas línguas e saberes.

\footnotetext{
${ }_{7}^{6}$ Ver Lei $10.639 / 03$ e Lei $11.645 / 08$.

7 O indígena Werá Djekupé (ou Marcelo Guarani) é uma liderança da aldeia Três Palmeiras, localizada em Santa Cruz, no norte do estado de Espírito Santo.
} 
A atividade do Cinema na Escola se caracterizou pela exibição de vídeos, filmes e documentários sobre a temática afro-indígena e contou com a colaboração dos alunos cursando o primeiro estágio docente I, diante do exercício da sua prática em sala de aula, tendo em vista que a tarefa do aluno era preparar uma aula com abordagem intercultural e utilizar o recurso pedagógico audiovisual.

Para finalizar, será apresentado o relato das observações discentes fruto do trabalho de campo, ainda em fase preliminar, com vistas a investigar processos educativos e interculturais em espaços não formais ${ }^{8}$, como, no caso do patrimônio campista, a Escola de Samba União da Esperança, uma das mais antigas e tradicionais escolas de samba da cidade, segundo a avaliação de seus membros, foliões e frequentadores. A narrativa a seguir expressa como a experiência foi compreendida pelo discente:

Enquanto bolsista do projeto tive a oportunidade de conhecer a União da Esperança, pois nunca havia entrado antes em uma escola de samba para ver samba, havia participado há alguns anos de um projeto social no local. A União, que apesar de ficar no mesmo bairro que o meu, sempre me foi algo a ser evitado. Creio que pela educação tradicional que recebi, onde me era ensinado a afastar tudo o que "desagradava a Deus". Entretanto, procurei me adaptar rápido ao ambiente, notei que o público era eminentemente habitante das redondezas, jovens e adultos, onde conheço pessoalmente alguns membros da bateria e alguns que compõem a velha guarda da escola (Aluno "W", do 4º período, 2015).

O exercício de estranhamento ocorreu na cerimônia de aniversário da agremiação, em que, para marcar a data, se celebrou na quadra uma ladainha a São Benedito, padroeiro da escola. O ritual apresentava diversas simbologias, como um altar com imagens de dois santos, São Benedito e São Sebastião, um copo de água, um jarro com flores tipo copo-de-leite e galhos de samambaia, além de uma taça vermelha com uma vela branca, grande e grossa. Notou-se também que, a cada chegada à quadra, as pessoas benziam-se em frente à imagem do Santo em plena devoção.

\footnotetext{
${ }^{8}$ Para este trabalho, consideramos como espaços não formais aqueles localizados fora do ambiente da escola tradicional e que não se encontram relacionados e/ou vinculados às regras do poder institucionalizado pelo Estado.
} 
O aluno ainda pontuou sobre o seu estranhamento, afirmando:

Em suma, a experiência foi enriquecedora e serviu para quebrar ainda mais as pré-noções que tinha, e ainda tenho um pouco, em relação ao samba e as religiões de matriz africana, tomando a alteridade, o estranhamento e a desnaturalização como princípios para a prática docente.

Nessa direção, ressalto a relevância de estimular saberes e práticas educativas relacionadas à memória e ao patrimônio cultural. Dessa forma, é possível contribuir com conhecimentos que se anunciam em experiências plurais sobre processos educacionais organizados fora da lógica do sistema regular de ensino, em que os conteúdos não sejam previamente definidos pelas diretrizes curriculares nacionais, mas, como propõe Mills (1975), que estejam relacionados às biografias dos alunos e ao contexto social em que se encontram, de modo que a prática educativa constituída na aula de Sociologia seja compreendida a partir de outras formas de apropriação do mundo.

\section{CONSIDERAÇÕES FINAIS}

$\mathrm{Em}$ todas as atividades mencionadas, a ideia foi proporcionar aos licenciandos algumas reflexões sobre as noções de memória e patrimônio como categorias circunstanciais. Nas situações que foram relatadas, a proposta foi a de estabelecer relações com o campo da educação, de maneira que esse entendimento contribua para a prática docente como professor de Sociologia no ensino médio. Além disso, ressaltamos a relevância do exercício da imaginação sociológica no planejamento das aulas, na elaboração de metodologias de ensino e estratégias didáticas, além da necessária reflexão sobre os conteúdos obrigatórios a serem lecionados, visando à proximidade com saberes e práticas habituais dos alunos.

A escolha dos conhecimentos que devem constituir o currículo e compor os conteúdos a serem trabalhados em sala de aula é uma tarefa que envolve a correlação de forças, disputas e negociações (APPLE, 1982). No sentido de manter 
o diálogo entre professor e escola sobre a prática docente, é importante nortear-se pelas Orientações Curriculares Nacionais para o Ensino Médio (OCNs), na medida em que esse documento traz princípios para o ensino de Sociologia, de modo que os conteúdos e metodológicos de ensino estejam sintonizados com os sentidos do ensino, das juventudes e das escolas. As OCNs propõem-se a ser um mapa, uma proposta para orientar o trabalho do professor, o que, talvez, não possa ser dito da BNCC (Base Nacional Curricular Comum) em discussão atualmente.

Ademais, o professor da disciplina deve participar e avaliar o que será ensinado e debatido na disciplina, bem como conhecer o espaço que a Sociologia vem ocupando nos currículos no decorrer de sua história. Estas são algumas tarefas promissoras para o professor da disciplina.

Contudo, é importante ressaltar que as limitações impostas à realização das atividades esbarraram, principalmente, em problemas concernentes à infraestrutura, seja nas escolas de ensino médio, seja na universidade. Além dessa questão, os jovens discentes que se encontram atuando na rede de ensino como professores já concursados alegam que esses tipos de projetos e propostas demandam tempo e apoio, conforme relata a aluna Y:

$\mathrm{Na}$ escola pública ainda não tive chance porque é muita coisa pra cumprir, um tal de prova, recuperação, recuperação da recuperação, etc., etc. que com uma aula na semana não tive chance ainda [...] sinto falta disso, proponho coisas diferentes, mas me vejo sozinha [...] vou resgatar o meu projeto e apresentar na escola particular.

Diante do exposto, é possível afirmar que as experiências desenvolvidas no curso de licenciatura propuseram um maior e melhor conhecimento do campo das ciências sociais e do exercício sociológico da criatividade e da imaginação mediante a prática educativa, na medida em que tomaram a memória e o patrimônio como campo de discursos e saberes profícuos, estimulando a pensar por meio do lúdico e do cotidiano.

No debate contemporâneo, os sentidos de memória e patrimônio se alargam, não sendo somente o que se herda, mas o bem constitutivo da consciência de um 
grupo, um campo de disputas e de negociações; um bem cultural que se articula ao seu conhecimento e ao seu uso social, à ciência e à consciência, ou seja, ao sentido político dado pelos grupos.

\section{REFERÊNCIAS}

ABREU, Regina; CHAGAS, Mário (Org.). Memória e Patrimônio: ensaios contemporâneos. 2. ed. Rio de Janeiro: Lamparina, 2009.

APPLE, Michael. Ideologia e Currículo. São Paulo: Brasiliense, 1982.

BOSI, Ecléa. O Tempo Vivo da Memória Social: ensaios de psicologia social. São Paulo: AE Ateliê, 2003.

BRASIL. Ministério da Educação. Secretaria de Educação Básica. Departamento de Políticas de Ensino Médio. Orientações Curriculares Nacionais do Ensino Médio. Ciências Humanas e suas Tecnologias. v. 3. Brasília, DF, 2006.

BRASIL. Constituição. Constituição da República Federativa do Brasil: promulgada em 5 de outubro de 1988. Brasília, DF: Senado, 1988 (art. 215 e 216).

FONSECA, Maria Cecília Londres. Para além da pedra e cal: por uma concepção ampla de patrimônio cultural. In: CHAGAS, Mário; ABREU, Regina (Org.). Memória e patrimônio: ensaios contemporâneos. Rio de Janeiro: Lamparina, 2003. p. 59-79.

GONÇALVES, José Reginaldo Santos. As transformações do patrimônio: da retórica da perda à reconstrução permanente. In: TAMASO, Izabela Maria; LIMA FILHO, Manuel Ferreira (Org.). Antropologia e Patrimônio Cultural: trajetórias e conceitos. Brasília: Associação Brasileira de Antropologia, 2012. p. 59-73.

GONÇALVES, José Reginaldo Santos. O patrimônio como categoria de pensamento. In: CHAGAS, Mário; ABREU, Regina (Org.). Memória e patrimônio: ensaios contemporâneos. Rio de Janeiro: Lamparina, 2003. p. 25-33.

GONDAR, Jô; DODEBEI, Vera (Org.). O que é memória social? 2. ed. Rio de Janeiro: Contra Capa Livraria/Programa de Pós-Graduação em Memória Social da Universidade Federal do Estado do Rio de Janeiro, 2005.

HALBWACHS, Maurice. A Memória Coletiva. São Paulo: Vértice, 1990.

MILLS, W. A Imaginação Sociológica. Rio de Janeiro: Zahar, 1975. 
NORA, Pierre. Entre História e Memória: a trajetória dos lugares. Revista Projeto História, São Paulo, n. 10, p. 01-22, dez. 1993.

PEREZ, Carmen Lucia Vidal; TAVARES, Maria Tereza Goudart; ARAUJO, Mairce da Silva. Memórias e Patrimônios: experiências em formação de professores. Rio de Janeiro: Eduerj, 2009.

POLLACK, Michael. Memória e Identidade Social. Revista Estudos Históricos, Rio de Janeiro, v. 5, n. 10,1992. p. 200-212.

SILVA, Ileizi Luciana Fiorelli. O Ensino das Ciências Sociais/Sociologia no Brasil: histórico e perspectivas. In: MORAES, Amaury C (Coord.). Sociologia: ensino médio. Brasília: Ministério da Educação, Secretaria de Educação Básica, 2010. p. 15-44. (Coleção Explorando o Ensino; v. 15).

TEIXEIRA, Simonne (Org.). Políticas Culturais: trajetórias e diálogos em Campos dos Goytacazes. Campos dos Goytacazes: EdUenf, 2014. 